\title{
Catastrophic Caustic Ingestion: A Case Report
}

\author{
Kerri L Bouchard* \\ University of Maryland Medical Center, Baltimore, USA
}

\begin{abstract}
Introduction: The majority of oral ingestion of caustic material by adults is intentional, and the aftermath varies widely with potentially fatal results. Injuries range from superficial burns of facial and oropharyngeal structures to extensive necrosis of the gastrointestinal tract. Management focuses on the identification of the ingested substance and prompt treatment and supportive care of the multiple complications stemming from the ingestion. Complications following caustic ingestion include both immediate and long term. Case presentation: A fifty-seven-year-old man presented following intentional ingestion of drain cleaner. The patient was intubated and underwent emergent esophagogastroduodenoscopy [EGD], which revealed extensive damage to his oesophagus and stomach. He survived his initial injury but had a prolonged hospital course and ultimately died after developing tracheoesophageal and bronchooesophageal fistulas which were too extensive for surgical repair. Conclusion: The sequelae of caustic ingestion can be minor or severe, both immediate and delayed. Despite appropriate prompt management and supportive care, patients may die as a result of the initial injury or subsequent complications.
\end{abstract}

Keywords: caustic ingestion, toxic ingestion, caustic injuries, suicide

Received: 28 December 2019 / Accepted: 3 April 2020

\section{INTRODUCTION}

Ingestion of caustic material is a medical emergency that can have devastating results, even with prompt, appropriate treatment. Sequelae of caustic ingestion include both immediate and long-term consequences. Immediate and early injuries of caustic ingestion range from varying degrees of facial and oropharyngeal burns to full-thickness necrosis of the oesophagus and stomach with possible perforation and ultimately, death [1]. Patients that survive caustic ingestion are subject to long term complications, including oesophageal strictures and cancer [2]. Ingestion of caustic substances in adults is typically intentional, and usually a suicide attempt, most often in those with psychiatric disorders or alcoholism [1-4].

\section{CASe Presentation}

A fifty-seven-year-old man presented to the emergency department [ED] of Harford Memorial Hospital, Havre de Grace, Maryland, United States of America, approximately five hours after an intentional ingestion of professional strength drain cleaner. He had a past medical history which included alcoholism, anxiety, depression, and prior suicide attempt.
At the time of his initial hospital examination, he was in respiratory distress with copious bloody oral secretions and oedema of his lips, tongue, chin, and neck. He was tachycardic, tachypneic, hypoxic, and normotensive. Laboratory results showed a leucocytosis, elevated lactate, and a blood alcohol content of 212 milligrams per 100 millilitres of blood. Urine toxicology was negative.

The first attempt at endotracheal intubation was unsuccessful due to severe erosion and bleeding of the oropharynx, and poor visualization of anatomical structures. The patient was successfully orally intubated with an 8-millimetre endotracheal tube on the second attempt.

Dexamethasone sodium phosphate (Pfizer, New York, New York, United States of America) 8 milligrams intravenously, was given as recommended by the Poison Control Centre. The patient was then transferred to the Critical Care Resuscitation Unit of The University of Maryland Medical Center, Baltimore, Maryland, United States of America, for further critical care management within a tertiary care center.

Esophagogastroduodenoscopy (EGD) performed five hours after initial presentation, demonstrated severely oedematous, friable mucosa of posterior oropharynx and epiglottis, diffusely inflamed oesophageal 
mucosa with diffuse ulceration and sloughing throughout entire oesophagus (Figures 1 and 2).

Due to the extent of the injury, only the proximal gastric body was examined and revealed diffuse gastritis with confluent ulceration. In accordance with Zargar's grading classification, the endoscopic evaluation revealed a Grade 3a caustic injury to the proximal and mid oesophagus, Grade 3b caustic injury to the lower oesophagus, consistent with liquefaction necrosis, and Grade 3a caustic injury to the proximal gastric body. The patient was placed on proton pump inhibitor infusion and started on empiric Ceftriaxone (Pfizer, New York, New York, United States of America), 1 gram intravenously every 24 hours, receiving 3 doses, one each



Fig. 1. EGD image of diffusely inflamed oesophageal mucosa

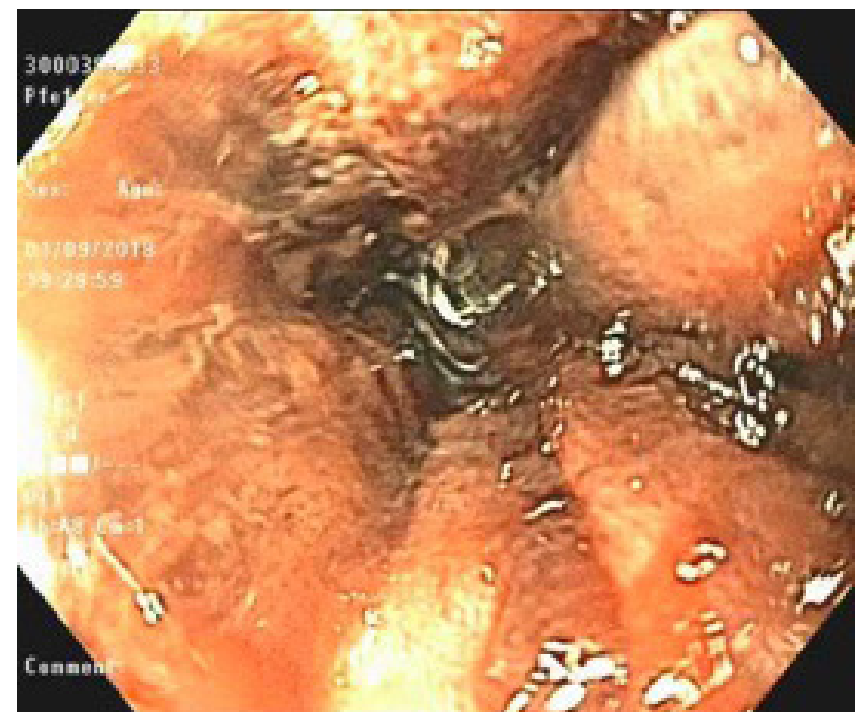

Fig. 2. EGD image of inflamed oesophageal mucosa with diffuse ulceration and sloughing starting on the day of admission, and days 1 and 2 following admission. Chest and abdominal radiographs demonstrated no evidence of free air or gastrointestinal perforation.

The patient was transferred to the hospital's Intensive Care Unit (ICU) on day one post-admission. Initial physical exam findings at this time, showed extensive burns and eschar to his lower lip, chin, and left cheek (Figure 3).

His tongue and visible oropharynx were oedematous with grey-black discolouration. Expiratory wheezes were auscultated throughout his lung fields, and dark red secretions were taken from the endotracheal tube [ETT].

Empiric antifungal coverage with fluconazole (Pfizer, New York, New York, United States of America), 100 milligrams intravenously every 24 hours was started on the day following admission and was continued for seven days due to high risk for oesophageal perforation.

Serial chest and abdominal radiographs were done to evaluate for evidence of gastrointestinal perforation (free air, pneumomediastinum). Radiographs were taken twice daily for three days, then daily for five days, and remained negative for evidence of gastrointestinal perforation. An enteral tube was not placed due to the risk of perforation.

A computed tomography [CT] of the chest with contrast, done two days after admission, showed oesophageal wall oedema, but no evidence of pneumomediasti-

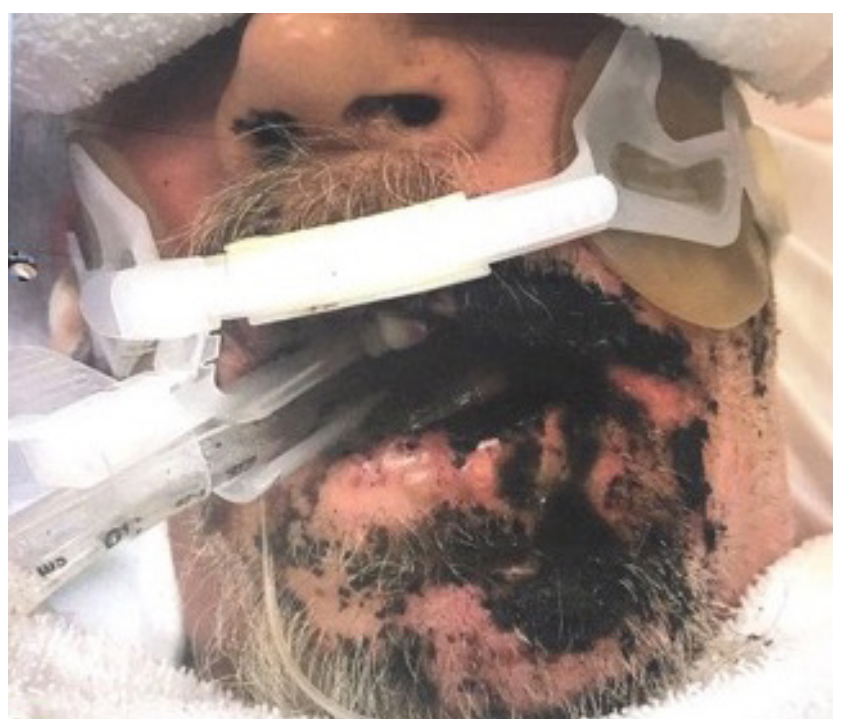

Fig. 3. Extensive burns and eschar to the patient's lower lip, chin, and left cheek 
num. CT of the chest demonstrated dependent bilateral lower lobe consolidation, consistent with aspiration pneumonitis/pneumonia.

Bronchoscopy, done three days post-admission revealed copious thick mucopurulent secretions throughout the bronchial tree and oedematous, erythematous, collapsible areas of friable, pale tissue, consistent with caustic pneumonitis.

The patient's stay in hospital was complicated by severe agitated delirium and alcohol withdrawal symptoms which required large doses of multiple analgesics and sedative agents (Table 1).

The patient developed hospital-acquired pneumonia which was treated with a course of cefepime (Pfizer, New York, New York), two grams intravenous every eight hours and metronidazole 500 milligrams every eight hours, starting on days nine post-admission and continuing to day sixteen post-admission.

All blood cultures and sputum cultures, taken on days $2,9,11,16$, and 18 post-admission, and bronchial culture, taken on days 3,16 , remained negative.

A peripherally inserted central venous catheter was inserted on day 7 for provision of total parenteral nutrition.

The patient received diuresis with furosemide (Pfizer, New York, New York), 20-80 milligrams intravenously 1-3 times daily on post-admission days eight through sixteen.
The patient could not be taken off mechanical ventilation. Sixteen days after admission, he underwent an EGD, which showed extensive total oesophageal necrosis (Zargar stage $3 \mathrm{~b}$ ), areas of healing gastric injury at the cardia near the gastroesophageal junction and in the pre-pyloric zone. A percutaneous endoscopic gastrostomy [PEG] tube was placed, and oesophageal dilation performed. Tracheostomy was performed using a hybrid-open approach, combined with percutaneous technique.

Approximately 30 hours postoperatively, copious green bilious secretions flowed from the tracheostomy tube.

Bronchoscopy was performed (via tracheostomy) and showed copious green-yellow secretions leaking down around the tracheal tube into the right mainstem bronchus with pooling of secretions in the right middle and lower lobes, which were suctioned. The left upper and lower lobes appeared clear of secretions. The bronchoscope was then withdrawn from the tracheostomy and advanced into to oropharynx with notation of erythematous, oedematous tissue of the epiglottis and vocal cords with diffuse tissue damage (Figures 4 and 5).

On day 17 post-admission, the patient became tachycardic and hypertensive with significant ventilator dyssynchrony. Physical exam revealed bloody drainage from percutaneous endoscopic gastrostomy tube insertion site and an audible air leak from tracheostomy and percutaneous endoscopic gastrostomy tube sites.

Table 1. Analgesic and sedative agents administered

\begin{tabular}{|c|c|c|c|c|c|}
\hline Drug & Route & Dose & Frequency & $\begin{array}{l}\text { Hospital } \\
\text { days }\end{array}$ & Manufacturer \\
\hline Fentanyl citrate & $\begin{array}{l}\text { Intravenous } \\
\text { infusion }\end{array}$ & $\begin{array}{c}\text { 100-300 milligrams/ } \\
\text { hour }\end{array}$ & $\begin{array}{l}\text { Continuous infu- } \\
\text { sion }\end{array}$ & $1-10$ & $\begin{array}{c}\text { Akorn, Inc., Lake Forest, } \\
\text { Illinois, USA }\end{array}$ \\
\hline propofol & $\begin{array}{l}\text { Intravenous } \\
\text { infusion }\end{array}$ & $\begin{array}{l}10 \text { to } 60 \text { micrograms/ } \\
\text { milligram/minute }\end{array}$ & $\begin{array}{l}\text { Continuous infu- } \\
\text { sion }\end{array}$ & $1-7,10-15$ & $\begin{array}{c}\text { Pfizer, New York, New York, } \\
\text { USA }\end{array}$ \\
\hline lorazepam & $\begin{array}{l}\text { Intravenous } \\
\text { injection }\end{array}$ & 1-6 milligrams & $\begin{array}{l}\text { Every } 4 \text { hours as } \\
\text { needed }\end{array}$ & $5-9$ & $\begin{array}{c}\text { Pfizer, New York, New York, } \\
\text { USA }\end{array}$ \\
\hline hydromorphone & $\begin{array}{l}\text { Intravenous } \\
\text { infusion }\end{array}$ & 4-15 milligrams/hour & $\begin{array}{l}\text { Continuous infu- } \\
\text { sion }\end{array}$ & $8,11-19$ & $\begin{array}{c}\text { Pfizer, New York, New York, } \\
\text { USA }\end{array}$ \\
\hline Hydromorphone & $\begin{array}{l}\text { Intravenous } \\
\text { injection }\end{array}$ & 1-5 milligrams & $\begin{array}{l}\text { Every } 1 \text { hour as } \\
\text { needed }\end{array}$ & 7-19 & $\begin{array}{c}\text { Pfizer, New York, New York, } \\
\text { USA }\end{array}$ \\
\hline $\begin{array}{l}\text { Haloperidol dec- } \\
\text { anoate }\end{array}$ & $\begin{array}{l}\text { Intravenous } \\
\text { injection }\end{array}$ & 10 milligrams & $\begin{array}{l}\text { Every } 4 \text { hours } \\
\text { around the clock } \\
\text { and as needed }\end{array}$ & 10-19 & $\begin{array}{l}\text { Fresenius Kabi, Lake Zurich, } \\
\text { Illinois, USA }\end{array}$ \\
\hline $\begin{array}{l}\text { Dexmedetomidine } \\
\text { hydrochloride }\end{array}$ & $\begin{array}{l}\text { Intravenous } \\
\text { infusion }\end{array}$ & $\begin{array}{l}\text { 0.4-1.5 micrograms } \\
\text { per kilogram per hour } \\
\text { (total } 39 \mathrm{mcg} \text { ) }\end{array}$ & $\begin{array}{l}\text { Continuous infu- } \\
\text { sion }\end{array}$ & 9,10 & $\begin{array}{l}\text { Fresenius Kabi, Lake Zurich, } \\
\text { Illinois, USA }\end{array}$ \\
\hline $\begin{array}{l}\text { Ketamine hydro- } \\
\text { chloride }\end{array}$ & $\begin{array}{l}\text { Intravenous } \\
\text { infusion }\end{array}$ & $\begin{array}{c}2 \text { milligrams/kilogram/ } \\
\text { hour }\end{array}$ & $\begin{array}{l}\text { Continuous infu- } \\
\text { sion }\end{array}$ & 14-19 & $\begin{array}{c}\text { Pfizer, New York, New York, } \\
\text { USA }\end{array}$ \\
\hline
\end{tabular}


A computed tomography (CT) scan done on day seventeen post-admission (day 1, post-operative) of the chest, abdomen and pelvis revealed an extensive tracheoesophageal fistula as well as a bronchooesophageal fistula at the level of left mainstem bronchus.

It was decided that the patient was not a candidate for operative intervention due to the massive extent of both the injuries and their anatomical location. After a discussion with the patient's family and with their informed consent, the patient was placed on comfort care. This included 30 percent supplemental oxygen via a tracheostomy collar for comfort and infusions of ketamine hydrochloride (Pfizer, New York, New York, United States of America), 2 milligrams per kilogram per hour and hydromorphone (Pfizer, New York, New York, United States of America), 15 milligrams per hour.

The patient was transferred to the inpatient hospice on day 23 , and he succumbed to his injuries twenty-five days after hospital admission.

\section{Discussion}

The majority of caustic ingestion involves oral consumption of strong acid or strong alkali substances, most often cleaning products. These materials cause injury through a chemical process with immediate damage to living tissue on contact. Oral ingestion of these substances leads to the destruction of soft tissues and

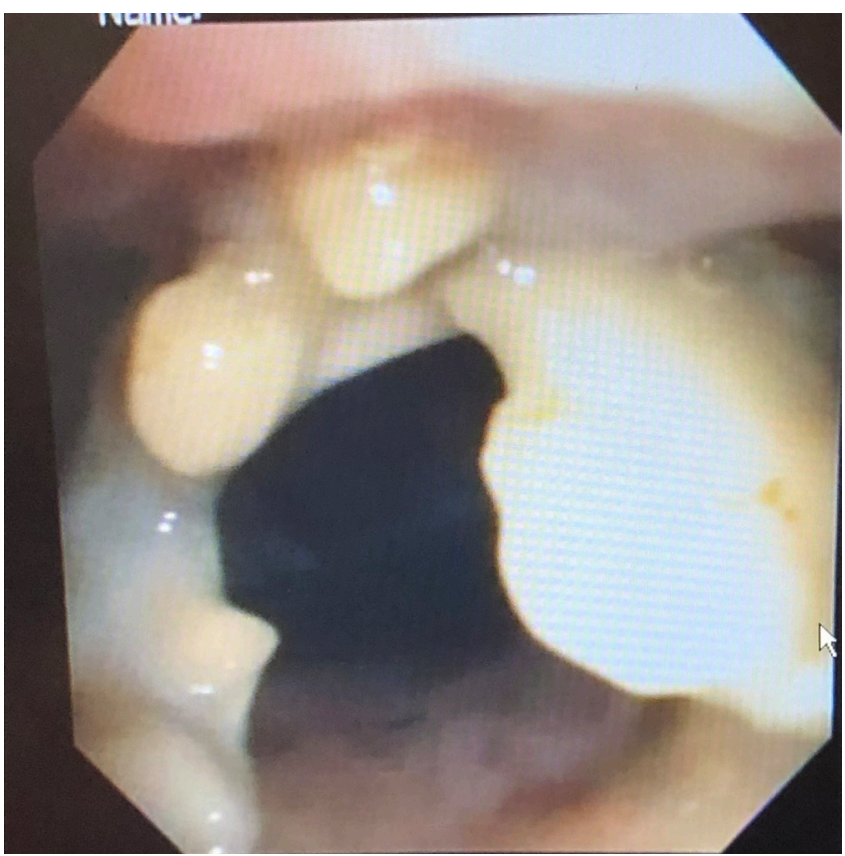

Fig. 4. Bronchoscopy image of oedematous tissue of the epiglottis with diffuse tissue damage mucous membranes of the face, oropharyngeal structures, airway, and gastrointestinal tract [2-5]. The extent and anatomical location of the injury are dependent on multiple factors, including the type of substance, formulation, amount, and the length of exposure [1-7].

Acids cause coagulation necrosis, a chemical process which produces an eschar which theoretically decreases penetration to deeper tissues $[3,4]$. Additional characteristics of acids include a strong odour and an unpleasant taste, decreased viscosity. Increased oesophageal transit, results in less oesophageal contact and injury, and therefore likely to cause more significant gastric injury $[2,4,5,7]$. There has been evidence that both strong acid and alkali ingestion can lead to full-thickness injury of the oesophageal and gastric mucosae [3,7]. Examples of strong acids include sulfuric and hydrochloric acids such as toilet bowl cleaners and rust remover [4].

In contrast to acids, alkaline substances cause liquefaction necrosis as a result of reactions between alkali, proteins, and fats. Liquefaction necrosis causes deeper tissue penetration and a higher probability of transmural injury [7]. Alkaline substances are usually colourless, relatively tasteless, and viscid [4,7]. Due to their increased viscosity, alkalis have a decreased transit time through the oesophagus with a resultant increase in oesophageal injury [6]. Examples of alkaline substances include sodium and potassium, such as oven cleaner, liquid drain cleaners [4].



Fig. 5. Bronchoscopy image of oedematous vocal cords with diffuse tissue damage 
Initial management of caustic injuries focuses on airway securement and haemodynamic stabilization. It is imperative to determine, if possible, both the agent, the amount, and time of ingestion, to guide management. Patients should be intubated early, preferably with fiberoptic laryngoscopy to allow for direct visualization of the epiglottis and larynx and minimize risk for further trauma [4,7]. A surgical airway may need to be performed in cases of profound oropharyngeal oedema. Subsequent management focuses on the determination of the extent of injury to the gastrointestinal tract, and ongoing management and supportive care of metabolic disorders, multisystem organ dysfunction, sepsis, aspiration pneumonia, and gastrointestinal perforation [2]. Oesophageal and gastric perforation can occur at any time within the first two weeks after ingestion [3].

Diagnostic and management strategies for caustic ingestion injuries vary, and a consensus is lacking. There is a lack of randomized control trials regarding the ideal management of caustic injuries [4]. EGD is considered the gold standard for diagnosis and to guide subsequent management, and should typically be done within twelve to forty-eight hours of ingestion [4,7]. The Zargar classification system is generally used to determine the extent of caustic injury (Table 2).

Endoscopy is not recommended on days five to fifteen post-ingestion due to an increased perforation risk [7]. The instances in which EGD are contraindicated are in hemodynamic instability, severe respiratory compromise, suspected perforation, and third-degree burns of the hypopharynx $[3,7]$.

A CT scan can provide a more detailed evaluation than an EGD, regarding the extent of transmural damage to oesophageal and gastric walls and degree of necrosis [2]. Serial plain chest and abdominal films should initially be obtained to evaluate for perforation, which would be suggested by mediastinal air on images $[3,4]$.

Table 2. Endoscopic grading of caustic injuries (Zargar classification) $[2,4,6]$

\begin{tabular}{ll} 
Grade & Characteristics \\
0 & Normal mucosa \\
1 & Superficial oedema and erythema \\
$2 a$ & $\begin{array}{l}\text { Friability, haemorrhages, superficial ulcer- } \\
\text { ations, exudates }\end{array}$ \\
$3 a$ & $\begin{array}{l}\text { Grade 2a plus deep and circumferential } \\
\text { ulcerations }\end{array}$ \\
$3 b$ & Extensive necrosis \\
\hline
\end{tabular}

Early, emergent surgery is indicated in patients with clinical or radiographic evidence of gastrointestinal perforation. Typically, exploratory laparotomy is performed with oesophagostomy or gastrectomy or more extensive resection [6]. The need for emergency reconstructive surgery for caustic injury has a global negative effect on survival and functional outcomes $[1,8]$.

Neutralizing agents are not recommended due to risk for additional injury due to exothermic reactions $[2-4,7]$. Nasal and oral gastric tubes are not routinely recommended due to possible stimulation of vomiting, which could result in further oesophageal injury secondary to re-exposure to caustic material [3,7]. Gastric acid suppression, such as $\mathrm{H} 2$ blocker or proton pump inhibitors, is often used to promote healing and prevent ulcers, although the efficacy of this has not been proven [7]. Nutrition provision should be established as soon as feasible, using a gastrointestinal tract, if at all possible.

Administration of systemic corticosteroids in caustic injuries has been contentious, has not been proven to prevent strictures, and is not routinely recommended $[1,7]$. Broad-spectrum antibiotics are sometimes used prophylactically but have not been shown to reduced stricture formation and are currently advised only if active infection is suspected [2-4].

In the present case, these two interventions were utilized despite the lack of evidence supporting their use. This deviation is related to the scarcity of randomized control trials, and agreed protocol management, regarding these types of injuries.

Oesophageal strictures are the most common late consequence of caustic injury [7].

Primary management of oesophageal strictures is oesophageal dilation $[1,2,7]$. Typically, dilation can be started after healing of acute injuries, usually, three to six weeks post-injury. Later initiation of dilation could cause more complications due to fibrosis and collagen deposition of the oesophageal wall [2]. Generally, dilations are done every one to three weeks, with the expectation of three to five sessions for adequate results [2]. Unfortunately, the incidence of perforation postdilation of corrosive strictures is higher than for other strictures $[1,2]$.

Oesophageal strictures are sometimes treated with stents or surgery. The efficacy of these procedures requires to be proven by further studies $[1,2,7]$. Other late complications of caustic injury include fistula formation and oesophageal malignancy [2]. 


\section{CONCLUSION}

Injuries due to caustic ingestion vary widely and can have potentially catastrophic results. Prompt identification of the ingested substance, determination of the degree of injury, and management of injuries and subsequent complications are essential. Despite appropriate diagnosis and management of caustic injuries, multiple complications, including death, can occur, in the weeks, months, and years following the initial injury.

\section{- CONFLICT OF INTEREST}

None to declare.

\section{REFERENCES}

1. Bonavina L, Chirica M, Skrobic O, et al. Foregut caustic injuries: results of the world society of emergency surgery consensus conference. World J Emerg Surg. 2015;10:44.

2. Chirica M, Bonavina L, Kelly MD, Sarfati E, Cattan P. Caustic ingestion. The Lancet. 2017 May;389(10083):2041-52.

3. Contini S, Scarpignato C. Caustic injury of the upper gastrointestinal tract: a comprehensive review. World J Gastroenterol. 2013 Jul 7;19(25):3918-30.

4. Lupa M, Magne J, Guarisco JL, Amedee R. Update on the Diagnosis and Treatment of Caustic Ingestion. Ochsner J. 2009;9(2):54-9.

5. Kluger Y, Ishay OB, Sartelli M, Katz A, Ansaloni L, Gomez CA, et al. Caustic ingestion management: world society of emergency surgery preliminary survey of expert opinion. World J Emerg Surg. 2015 Oct 16;10(1):48.

6. Alipour Faz A, Arsan F, Peyvandi H, Oroei M, shafagh O, Peyvandi $M$, et al. Epidemiologic Features and Outcomes of Caustic Ingestions; a 10-Year Cross-Sectional Study. Emerg (Tehran) [Internet]. 2017 [cited 2019 May 4];5(1). Available from: https://www.ncbi.nlm.nih.gov/pmc/articles/PMC5585826/

7. De Lusong MAA, Timbol ABG, Tuazon DJS. Management of esophageal caustic injury. World J Gastrointest Pharmacol Ther. 2017 May 6;8(2):90-8.

8. Chirica M, Resche-Rigon M, Bongrand NM, Zohar S, Halimi B, Gornet JM, et al. Surgery for caustic injuries of the upper gastrointestinal tract. Ann Surg. 2012 Dec;256(6):994-1001. 